\title{
A REPARTIÇÃO E A DESTINAÇÃO DA RECEITA DAS CUSTAS JUDICIAIS QUINZE ANOS APÓS A REFORMA DO JUDICIÁRIO
}

\section{Guilherme Carneiro Leão Farias ${ }^{1}$}

Resumo: O objetivo do presente artigo é determinar, em 2020, o estágio de efetivação da vinculação da receita de custas judiciais exclusivamente ao custeio dos serviços afetos às atividades específicas da Justiça. Esse objetivo foi perseguido por meio de pesquisa descritiva e quantitativo-qualitativa, baseada em coleta de dados legislativos e em revisão de literatura. Os resultados obtidos indicam que 13 dos 27 entes federativos competentes para arrecadar essa receita tributária descumprem essa vinculação constitucional $(48,15 \%)$. Dessa forma, conclui-se que o grau de efetivação da regra do art. 98, § $2^{\circ}$, da CRFB ainda é insatisfatório.

Palavras-chave: Taxa Judiciária; Jurisdição; Vinculação; Fundos; Autonomia.

\section{THE BREAKDOWN AND THE DESTINATION OF THE JUDICIAL FEES' REVENUE FIFTEEN YEARS AFTER THE REFORM OF THE JUDICIARY}

\begin{abstract}
The purpose of this article is to determine, in 2020, the stage of effectuation of the earmarking of judicial fees' revenue exclusively to the cost of services related to specific activities of Justice. This objective was pursued through descriptive and quantitativequalitative research, based on legislative data collection and literature review. The results obtained indicate that 13 of the 27 federative entities competent to collect that tax revenue fail to comply with that constitutional earmarking (48.15\%). Thus, it is concluded that the degree of effectiveness of the rule of article 98, paragraph $2 \mathrm{nd}$, of the Constitution is still unsatisfactory.
\end{abstract}

Keywords: Court Costs; Jurisdiction; Earmarking; Funds; Autonomy.

\section{INTRODUÇÃO}

Promulgada após mais de doze anos de tramitação no Congresso Nacional, a Emenda Constitucional (EC) n. 45, de 30 de dezembro de 2004, ficou conhecida como a da Reforma do Judiciário, porque, entre outras alterações promovidas na Constituição da República Federativa do Brasil, de 5 de outubro de 1988 (CRFB), tornou explícita a garantia fundamental à duração razoável do processo e aos meios que garantam a celeridade de sua tramitação (art. 5 , LXXVIII, da CRFB) e criou a Súmula Vinculante (art. 103-A da CRFB) e

\footnotetext{
${ }^{1}$ Mestrando em Direito e Políticas Públicas do Programa de Pós-graduação em Direito do Centro de Ciências Jurídicas e Políticas da Universidade Federal do Estado do Rio de Janeiro. Bacharel em Direito pela Universidade do Estado do Rio de Janeiro. Advogado empregado público. Endereço postal: Rua Leopoldo Miguez, número 112, apartamento 501, Copacabana, Rio de Janeiro, RJ, Brasil, CEP 22060-020. Endereços eletrônicos: guileao@uol.com.br; e guilherme.leao@edu.unirio.br.
} 
o Conselho Nacional de Justiça - CNJ (art. 103-B da CRFB). Outra inovação não menos relevante, porém pouco debatida em sede doutrinária, foi a destinação das custas e dos emolumentos exclusivamente aos serviços afetos às atividades específicas da Justiça (art. 98, $\S 2^{\circ}$, da CRFB).

Oriunda de emenda parlamentar aditiva apresentada em 30 de abril de 1999 e adotada em 14 de dezembro de 1999 no Substitutivo da Comissão Especial destinada a oferecer parecer sobre a Proposta de Emenda à Constituição (PEC) n. 96/1992 (BRASIL, 1999, p. 99, 110, 265, 280, 381, 434 e 531), essa nova hipótese de vinculação constitucional de receita tributária foi concebida como um reforço à autonomia financeira do Poder Judiciário (art. 99, caput, da CRFB) (MENDES et al., 2009, p. 977; MORAES, 2017, p. 535; TORRES, 2008, p. 345) e como um meio de assegurar recursos suficientes para a efetivação da garantia ao acesso à jurisdição célere, como os relacionados à informatização do processo judicial (Lei n. 11.419/2006).

Nesse contexto, coloca-se como problema de pesquisa se, em 2020, passados mais de quinze anos da entrada em vigor da EC n. 45/2004, a regra do art. 98, $\S 2^{\circ}$, da CRFB tem ou não tem sido observada pela União e pelos Estados-membros enquanto entes federativos incumbidos de organizar e manter os órgãos do Poder Judiciário (art. 21, XIII, 92, I a VII, e 125, caput, da CRFB) e, como consequência, competentes para instituir e arrecadar as taxas pela prestação, efetiva ou potencial, de serviços públicos específicos e divisíveis de natureza judicial (art. 145, II, da CRFB).

O objetivo do presente artigo é, pois, determinar o estágio de efetivação dessa vinculação constitucional no ano de 2020, por meio da análise da compatibilidade dos preceitos legais federais e estaduais que dispõem sobre a repartição e a destinação da receita oriunda da prestação de serviços pelos órgãos jurisdicionais do Poder Judiciário com a regra do art. 98, § $2^{\circ}$, da CRFB.

A hipótese adotada é a de que a efetivação completa da regra do art. $98, \S 2^{\circ}$, da CRFB, ainda não foi alcançada, porque parcela relevante (superior a 25\%) desses preceitos legais federais e estaduais padece de algum vício de inconstitucionalidade. Essa invalidade perante a Constituição da República pode ser: a) formal, por desrespeito à iniciativa privativa dos tribunais de proposição relacionada à autonomia administrativa e financeira do Poder Judiciário (art. 99, caput e $\S \S 1^{\circ}$ e $2^{\circ}$, da CRFB); e/ou b) material: b.1) por repartição da receita das custas judiciais com órgãos e entidades não integrantes do Poder Judiciário (art. 
92, I a VII, da CRFB) nem das Funções Essenciais à Justiça (Ministério Público, Advocacia Pública, Advocacia e Defensoria Pública); e/ou b.2) por destinação de parte dessa receita tributária a despesas que não se enquadrem no conceito legal de despesas correntes de custeio (art. 12, § $1^{\text {o; }}$ e 13 da Lei n. 4.320/1964) dos serviços diretamente relacionados à prestação jurisdicional.

O referencial teórico abrange as ideias de supremacia constitucional da Teoria Pura do Direito (KELSEN, 2009), de autonomia financeira da Teoria da Separação dos Poderes (MONTESQUIEU, 2015) e de custo dos direitos (HOLMES \& SUNSTEIN, 2019) da Análise Econômica do Direito (POSNER, 2014).

A pesquisa pode ser classificada como descritiva quanto aos objetivos e quantitativoqualitativa quanto à abordagem. Baseou-se em coleta de dados em atos normativos constitucionais e infraconstitucionais, disponíveis em sítios oficiais mantidos pelos três Poderes da União e dos Estados-membros, bem como em decisões do Supremo Tribunal Federal e revisão de literatura especializada em Direito Administrativo, Constitucional, Financeiro, Processual e Tributário, publicada, eletrônica ou fisicamente, na forma de artigos científicos, cursos, dicionários jurídicos e manuais.

A próxima seção apresentará as premissas teóricas para que sejam considerados recepcionados ou válidos, conforme o caso, a partir da entrada em vigor da EC n. 45/2004, os dispositivos legais emanados da União e dos Estados-membros que disciplinam a repartição e a destinação da receita de custas judiciais. Essas premissas nortearam a interpretação dos resultados obtidos, que serão apresentados na seção 3 .

\section{PREMISSAS PARA A PRETENDIDA ANÁLISE DE CONSTITUCIONALIDADE}

A partir da análise doutrina e da jurisprudência, é possível afirmar que a compatibilidade com a regra do art. $98, \S 2^{\circ}$, da CRFB pressupõe a (1) vinculação a fundo especial ou a ação ou programa na lei orçamentária anual, (2) por meio de lei em sentido formal, (3) oriunda de proposição do Tribunal respectivo, (4) da integralidade (5) da receita pública auferida a título de taxas de serviços judiciários judiciais (6) em despesas de custeio das funções típicas dos órgãos jurisdicionais do Poder Judiciário, (7) admitida a destinação de fração desse montante ao custeio das funções típicas dos órgãos de atuação e execução das Funções Essenciais à Justiça. 
A primeira premissa está relacionada à modalidade de gestão de recursos do Tesouro Nacional ou do Estado-membro a ser adotada para vincular as custas judiciais ao custeio dos serviços afetos às atividades específicas da Justiça. Apesar de ser desencorajada pelos estudiosos das finanças públicas, em razão de seus altos custos operacionais em comparação aos programas orçamentários (BASSI, 2019, p. 45-46; COSTA, 2012, p. 17-18; COSTA, 2017, p. 30; SANCHES, 2002, p. 275), a opção pelos fundos especiais é amplamente prevalente em matéria de reforço à autonomia financeira das instituições envolvidas na prestação jurisdicional. Por essa razão, inclusive, o Constituinte Derivado excepcionou da desvinculação de receitas dos Estados e do Distrito Federal (DRE) fundos instituídos pelo Poder Judiciário, pelo Ministério Público, pelas Defensorias Públicas e pelas ProcuradoriasGerais dos Estados e do Distrito Federal (art. 76-A, parágrafo único, V, do Ato das Disposições Constitucionais Transitórias - ADCT, incluído pelo art. $2^{\circ}$ da EC n. 93, de 8 de setembro de 2016).

Todos os 26 Estados-membros já possuem ao menos um fundo instituído pelo Poder Judiciário. Com apenas um fundo: Amazonas $^{2}$, Espírito Santo $^{3}$, Goiás ${ }^{4}$, Mato Grosso ${ }^{5}$, Mato Grosso do Sul $^{6}$, Minas Gerais ${ }^{7}$, Pará $^{8}$, Piauí ${ }^{9}$, Rondônia ${ }^{10}$, Roraima ${ }^{11}$, Santa Catarina ${ }^{12}$, São Paulo $^{13}$ e Sergipe ${ }^{14}$. Com dois fundos: Paraíba ${ }^{15}$, Pernambuco ${ }^{16}$, Rio Grande do Norte ${ }^{17}$ e Rio Grande do Sul ${ }^{18}$. Com três fundos: Acre ${ }^{19}$, Alagoas ${ }^{20}$, Amapá $^{21}$, Bahia ${ }^{22}$, Ceará ${ }^{23}$ e Rio de Janeiro $^{24}$. Com quatro fundos: Maranhão ${ }^{25}$, Paraná $^{26}$ e Tocantins ${ }^{27}$.

\footnotetext{
${ }^{2}$ Fundo de Modernização e Reaparelhamento do Poder Judiciário Estadual (FUNJEAM).

${ }^{3}$ Fundo Especial do Poder Judiciário (FUNEPJ).

${ }^{4}$ Fundo Especial de Reaparelhamento e Modernização do Poder Judiciário (FUNDES-PJ).

${ }^{5}$ Fundo de Apoio ao Judiciário (FUNAJURIS).

${ }^{6}$ Fundo Especial para o Desenvolvimento e o Aperfeiçoamento das Atividades dos Juizados Especiais Cíveis e Criminais (FUNJECC).

${ }^{7}$ Fundo Especial do Poder Judiciário do Estado de Minas Gerais (FEPJ).

${ }^{8}$ Fundo de Reaparelhamento do Judiciário (FRJ).

${ }^{9}$ Fundo Especial de Reaparelhamento e Modernização do Poder Judiciário do Estado do Piauí (FERMOJUPI).

${ }^{10}$ Fundo de Informatização, Edificação e Aperfeiçoamento dos Serviços Judiciários (FUJU).

${ }^{11}$ Fundo Especial do Poder Judiciário de Roraima (FUNDEJURR).

${ }^{12}$ Fundo de Reaparelhamento da Justiça (FRJ).

${ }^{13}$ Fundo Especial de Despesa do Tribunal de Justiça (FEDTJ).

${ }^{14}$ Fundo Especial de Recursos e de Despesas do Tribunal de Justiça do Estado de Sergipe (FERD).

${ }^{15}$ Fundo Especial do Poder Judiciário (FEPJ) e Fundo de Apoio ao Registro das Pessoas Naturais (FARPEN).

${ }^{16}$ Fundo Especial de Reaparelhamento e Modernização do Poder Judiciário do Estado de Pernambuco (FERMPJPE) e Fundo Estadual de Segurança dos Magistrados (FUNSEG).

${ }^{17}$ Fundo de Desenvolvimento da Justiça do Poder Judiciário do Rio Grande do Norte (FDJ) e Fundo Estadual de Segurança dos Magistrados (FUNSEG).

${ }^{18}$ Fundo de Reaparelhamento do Poder Judiciário (FRPJ) e Fundo Notarial e Registral (FUNORE).

${ }^{19}$ Fundo Especial do Poder Judiciário (FUNEJ), Fundo Estadual de Segurança dos Magistrados (FUNSEG) e Fundo Especial de Compensação (FECOM).
} 
Todos os 26 Estados-membros já possuem ao menos um fundo instituído pelo Ministério Público. Com apenas um fundo: $\operatorname{Acre}^{28}$, Alagoas $^{29}$, Amazonas $^{30}$, Bahia ${ }^{31}$, Espírito Santo $^{32}$, Goiás ${ }^{33}$, Maranhão ${ }^{34}$, Mato Grosso ${ }^{35}$, Mato Grosso do $\mathrm{Sul}^{36}$, Minas Gerais ${ }^{37}$, Pará ${ }^{38}$, Paraná $^{39}$, Pernambuco ${ }^{40}$, Rio Grande do Norte ${ }^{41}$, Rondônia ${ }^{42}$, Roraima ${ }^{43}$ e Tocantins ${ }^{44}$. Com dois fundos: Amapá ${ }^{45}$, Paraíba ${ }^{46}$, Piauí ${ }^{47}$, Rio de Janeiro ${ }^{48}$, Rio Grande do Sul ${ }^{49}$ e São Paulo ${ }^{50}$. Com três fundos: Ceará ${ }^{51}$ e Sergipe ${ }^{52}$. Com quatro fundos Santa Catarina ${ }^{53}$.

\footnotetext{
${ }^{20}$ Fundo Especial de Modernização do Poder Judiciário (FUNJURIS), Fundo Especial da Escola Superior da Magistratura do Estado de Alagoas (FUNDESMAL) e Fundo Estadual de Segurança dos Magistrados (FUNSEG).

${ }^{21}$ Fundo de Manutenção e Reaparelhamento da Justiça (FMRJ), Fundo de Apoio aos Juizados Especiais da Infância e da Juventude das Comarcas do Estado do Amapá (FAJIJ) e Fundo de Estruturação do Registro Civil
} (FERC).

${ }^{22}$ Fundo de Aparelhamento Judiciário (FAJ), Fundo Estadual de Segurança dos Magistrados (FUNSEG-BA) e Fundo Especial de Compensação (FECOM).

${ }^{23}$ Fundo Especial de Reaparelhamento e Modernização do Poder Judiciário (FERMOJU), Fundo Estadual de Segurança dos Magistrados (FUNSEG-JE) e Fundo Especial de Custeio das Despesas com Diligências dos Oficiais de Justiça.

${ }^{24}$ Fundo Especial da Escola da Magistratura do Estado do Rio de Janeiro (Fundo EMERJ), Fundo Especial do Tribunal de Justiça (FETJ) e Fundo de Apoio aos Registradores Civis das Pessoas Naturais do Estado do Rio de Janeiro (FUNARPEN/RJ).

${ }^{25}$ Fundo Especial de Modernização e Reaparelhamento Judiciário (FERJ), Fundo Especial da Escola Superior da Magistratura do Estado do Maranhão (Fundo ESMAM), Fundo Especial de Serventias de Registro Civil de Pessoas Naturais do Estado do Maranhão e Fundo de Segurança dos Magistrados do Maranhão (FUNSEG-JE).

${ }^{26}$ Fundo Rotativo, Fundo de Reequipamento do Poder Judiciário (FUNREJUS), Fundo da Justiça (FUNJUS) e Fundo Estadual de Segurança dos Magistrados (FUNSEG).

${ }^{27}$ Fundo Especial de Modernização e Aprimoramento do Poder Judiciário (FUNJURIS-TO), Fundo Estadual de Segurança dos Magistrados (FUNSEG), Fundo Especial de Compensação da Gratuidade dos Atos do Registro Civil de Pessoas Naturais (FUNCIVIL) e Fundo destinado à compensação dos custos referentes aos atos registrais da Regularização Fundiária Urbana de Interesse Social (Reurb-S).

${ }^{28}$ Fundo Especial do Ministério Público do Estado do Acre (FUNEMP-AC).

${ }^{29}$ Fundo Especial do Ministério Público do Estado de Alagoas (FUNPEAL).

${ }^{30}$ Fundo de Apoio do Ministério Público do Amazonas (FAMP/AM).

${ }^{31}$ Fundo de Modernização do Ministério Público do Estado da Bahia (FMMP/BA).

${ }^{32}$ Fundo Especial do Ministério Público do Estado do Espírito Santo (FUNEMP).

${ }^{33}$ Fundo para Reconstituição de Bens Lesados (FRBL).

${ }^{34}$ Fundo Especial do Ministério Público (FEMPE).

${ }^{35}$ Fundo do Ministério Público do Estado de Mato Grosso (FUNAMP).

${ }^{36}$ Fundo Especial de Apoio e Desenvolvimento do Ministério Público (FEADPMP/MS).

${ }^{37}$ Fundo Especial do Ministério Público do Estado de Minas Gerais (FUNEMP).

${ }_{38}^{38}$ Fundo de Reaparelhamento do Ministério Público do Estado do Pará.

${ }^{39}$ Fundo Especial do Ministério Público do Estado do Paraná (FUEMP/PR).

${ }^{40}$ Fundo de Desenvolvimento Institucional do Ministério Público de Pernambuco (FDIMPPE)

${ }^{41}$ Fundo de Reaparelhamento do Ministério Público (FRMP).

${ }^{42}$ Fundo de Desenvolvimento Institucional do Ministério Público do Estado de Rondônia (FUNDIMPER).

${ }^{43}$ Fundo Especial do Ministério Público do Estado de Roraima (FUEMP/RR).

${ }^{44}$ Fundo Especial do Centro de Estudos Jurídicos e Aperfeiçoamento do Ministério Público do Estado de Tocantins (FUMP).

${ }^{45}$ Fundo Especial de Apoio e Desenvolvimento do Ministério Público do Estado do Amapá (FEMPAP) e Fundo de Combate à Improbidade Administrativa e à Corrupção do Ministério Público do Estado do Amapá (FUNCIAC).

${ }^{46}$ Fundo Especial do Ministério Público (FEMPE) e Fundo Especial de Proteção dos Bens, Valores e Interesses Difusos. 
À exceção de Maranhão e Minas Gerais, todos os demais 24 Estados-membros possuem fundos instituídos pela Procuradoria-Geral do Estado. Com apenas um fundo: Acre $^{54}$, Alagoas ${ }^{55}$, Amapá ${ }^{56}$, Amazonas ${ }^{57}$, Bahia $^{58}$, Ceará ${ }^{59}$, Espírito Santo ${ }^{60}$, Goiás ${ }^{61}$, Mato Grosso $^{62}$, Mato Grosso do $\mathrm{Sul}^{63}$, Pará $^{64}$, Paraíba ${ }^{65}$, Paraná ${ }^{66}$, Pernambuco ${ }^{67}$, Piauí ${ }^{68}$, Rio de Janeiro $^{69}$, Rio Grande do Sul $^{70}$, Rondônia ${ }^{71}$, Roraima ${ }^{72}$, Santa Catarina ${ }^{73}$, Sergipe ${ }^{74}$ e Tocantins $^{75}$. Com dois fundos: São Paulo ${ }^{76}$.

À exceção de Minas Gerais, todos os demais 25 Estados-membros possuem fundos instituídos pela Defensoria Pública. Com apenas um fundo: Acre $^{77}$, Alagoas ${ }^{78}$, Amapá ${ }^{79}$,

\footnotetext{
${ }^{47}$ Fundo de Modernização do Ministério Público do Estado do Piauí (FMMP/PI) e Fundo Estadual de Proteção e Defesa do Consumidor (FPDC).

${ }^{48}$ Fundo Orçamentário Especial do Centro de Estados Jurídicos da Procuradoria-Geral da Justiça e Fundo Especial do Ministério Público (FEMP).

${ }^{49}$ Fundo de Reaparelhamento do Ministério Público (FRMP) e Fundo de Reaparelhamento do Ministério Público (FRMP).

${ }^{50}$ Fundo Especial do Centro de Estudos e Aperfeiçoamento do Ministério Público de São Paulo e Fundo Especial de Despesa do Ministério Público do Estado de São Paulo.

${ }^{51}$ Fundo de Manutenção da Escola Superior do Ministério Público do Estado do Ceará, Fundo de Segurança Institucional e Inteligência do Ministério Público do Estado do Ceará (FUNSIT) e Fundo de Reaparelhamento e Modernização do Ministério Público do Estado do Ceará (FRMMP/CE).

${ }^{52}$ Fundo Orçamentário Especial da Escola Superior do Ministério Público, Fundo Especial do Ministério Público do Estado de Sergipe (FEMP/SE) e Fundo para Reconstituição de Bens Lesados (FRBL).

${ }^{53}$ Fundo de Reaparelhamento da Justiça (FRJ), Fundo Especial de Modernização e Reaparelhamento do Ministério Público, Fundo Especial do Centro de Estudos e Aperfeiçoamento Funcional e Fundo para Reconstituição de Bens Lesados (FRBL).

${ }^{54}$ Fundo Orçamentário Especial.

${ }^{55}$ Fundo de Modernização da Procuradoria-Geral do Estado (FUNPGE).

${ }^{56}$ Fundo Especial de Aparelhamento e Modernização da Procuradoria-Geral do Estado (FUNDOPGE).

${ }^{57}$ Fundo Especial da Procuradoria Geral do Estado (FUNDPGE).

${ }^{58}$ Fundo de Modernização da Procuradoria Geral do Estado (FMPGE).

${ }^{59}$ Fundo de Modernização e Reaparelhamento da Procuradoria Geral do estado do Ceará (FUNPECE).

${ }^{60}$ Fundo de Modernização e Incentivo à Cobrança da Dívida Ativa e de Reestruturação Administrativa da Procuradoria Geral do Estado (FUNCAD).

${ }^{61}$ Fundo de Manutenção e Reaparelhamento da Procuradoria-Geral do Estado (FUNPROGE).

${ }^{62}$ Fundo de Aperfeiçoamento dos Serviços Jurídicos da Procuradoria-Geral do Estado (FUNJUS).

${ }^{63}$ Fundo Especial da Procuradoria-Geral do Estado (FUNDE-PGE).

${ }^{64}$ Fundo Especial da Procuradoria Geral do Estado.

${ }^{65}$ Fundo de Modernização e Reaparelhamento da Procuradoria Geral do Estado da Paraíba.

${ }^{66}$ Fundo Especial da Procuradoria Geral do Estado do Paraná (FEPGE/PR).

${ }^{67}$ Fundo Especial de Sucumbência Processual do Estado de Pernambuco (FESPEP).

${ }^{68}$ Fundo de Modernização da Procuradoria-Geral do Estado (FMPGE).

${ }^{69}$ Fundo Especial da Procuradoria Geral do Estado do Rio de Janeiro (FUNPERJ).

${ }^{70}$ Fundo de Reaparelhamento da Procuradoria-Geral do Estado (FURPGE).

${ }^{71}$ Fundo Especial de Modernização da Procuradoria-Geral do Estado de Rondônia (FUMORPGE).

${ }^{72}$ Fundo Especial da Procuradoria-Geral do Estado de Roraima (FUNDEPRO).

${ }_{74}^{73}$ Fundo Especial de Estudos Jurídicos e de Reaparelhamento (FUNJURE).

${ }^{74}$ Fundo TCE-PGE.

${ }^{75}$ Fundo Estadual de Modernização Jurídica (FEMJ).

${ }^{76}$ Fundo Especial de Despesas do Centro de Estudos e Fundo Especial da Procuradoria Geral do Estado (FUNPROGESP).

${ }^{77}$ Fundo Orçamentário Especial.
} 
Amazonas $^{80}$, Bahia $^{81}$, Ceará ${ }^{82}$, Espírito Santo ${ }^{83}$, Goiás ${ }^{84}$, Maranhão ${ }^{85}$, Mato Grosso ${ }^{86}$, Mato Grosso do Sul $^{87}$, Pará $^{88}$, Paraíba ${ }^{89}$, Pernambuco ${ }^{90}$, Piauí ${ }^{91}$, Rio Grande do Norte ${ }^{92}$, Rio Grande do Norte ${ }^{93}$, Rio Grande do Sul $^{94}$, Rondônia ${ }^{95}$, Roraima ${ }^{96}$, Santa Catarina ${ }^{97}$, Sergipe ${ }^{98}$ e Tocantins $^{99}$. Com dois fundos: Paraná ${ }^{100}$, Rio de Janeiro ${ }^{101}$ e São Paulo ${ }^{102}$.

A segunda premissa está relacionada à legalidade estrita em matéria de finanças pública, que veda, sem prévia autorização legislativa: o início de programa e projetos não incluídos na lei orçamentária; a abertura de crédito suplementar ou especial; a transposição, o remanejamento ou a transferência de recursos de uma categoria de programação para outra ou de um órgão para outro; e a instituição de fundo de qualquer natureza sem prévia autorização legislativa (art. 167, I, V, VI e IX, da CRFB).

A terceira premissa refere-se ao fato de competir privativamente ao Poder Judiciário deflagrar o processo legislativo em matérias relacionadas a sua autonomia administrativa e financeira (art. 99, caput e $\S \S 1^{\circ}$ e $2^{\circ}$, da CRFB). A vinculação do art. $98, \S 2^{\circ}$, da CRFB foi concebida como um reforço a essa autonomia (MENDES et al., 2009, p. 977; MORAES, 2017, p. 535; TORRES, 2008, p. 345), cabendo, pois, a partir da promulgação da EC n.

\footnotetext{
${ }^{78}$ Fundo de Modernização da Defensoria Pública do Estado de Alagoas (FUNDEPAL).

${ }^{79}$ Fundo Especial da Defensoria Pública (FEDP).

${ }^{80}$ Fundo Especial da Defensoria Pública do Estado do Amazonas (FUNDPAM).

${ }^{81}$ Fundo de Assistência Judiciária da Defensoria Pública do Estado da Bahia (FAJDPE/BA).

${ }^{82}$ Fundo de Apoio e Aparelhamento da Defensoria Pública-Geral do Estado do Ceará (FAADEP).

${ }^{83}$ Fundo de Aparelhamento da Defensoria Pública (FADESPES).

${ }^{84}$ Fundo de Manutenção e Reaparelhamento da Defensoria Pública do Estado de Goiás (FUNDEPEG).

${ }^{85}$ Fundo de Aparelhamento da Defensoria Pública do Estado (FADEP).

${ }^{86}$ Fundo de Aperfeiçoamento e Desenvolvimento das Atividades da Defensoria Pública do Estado de Mato Grosso (FUNADEP).

87 Fundo Especial para o Aperfeiçoamento e o Desenvolvimento das Atividades da Defensoria Pública (FUNADEP).

${ }^{88}$ Fundo Estadual da Defensoria Pública (FUNDEP).

${ }^{89}$ Fundo Especial da Defensoria Pública.

${ }^{90}$ Fundo de Modernização da Defensoria Pública do Estado de Pernambuco.

${ }^{91}$ Fundo de Modernização e Aparelhamento da Defensoria Pública do Estado do Piauí (FMADPEP).

${ }^{92}$ Fundo de Manutenção e Aparelhamento da Defensoria Pública Geral do Estado (FUMADEP).

93 Fundo de Aperfeiçoamento Funcional e Aparelhamento Administrativo da Procuradoria-Geral do Estado (FUNAF).

${ }^{94}$ Fundo de Aparelhamento da Defensoria Pública (FADEP).

${ }^{95}$ Fundo Especial da Defensoria Pública do Estado de Rondônia (FUNDEP).

${ }^{96}$ Fundo Especial da Defensoria Pública do Estado de Roraima (FUNDPE-RR).

${ }^{97}$ Fundo de Aparelhamento da Defensoria Pública do Estado de Santa Catarina (FADEP).

${ }^{98}$ Fundo de Modernização e Aparelhamento da Defensoria Pública do Estado de Sergipe (FUNDEPES).

${ }^{99}$ Fundo Estadual de Defensoria Pública (FUNDEP).

${ }^{100}$ Fundo da Defensoria Pública do Estado do Paraná (FADEP) e Fundo Rotativo.

${ }^{101}$ Fundo Orçamentário Especial do Centro de Estudos Jurídicos da Defensoria Pública Geral do Estado do Rio de Janeiro e Fundo Especial da Defensoria Pública do Estado do Rio de Janeiro (FUNDPERJ).

${ }^{102}$ Fundo de Assistência Judiciária (FAJ) e Fundo de Despesas da Escola da Defensoria Pública do Estado.
} 
45/2004, apenas aos Tribunais apresentar ao Poder Legislativo proposições que repercutam na repartição e na destinação da receita de custas e emolumentos.

A quarta premissa refere-se à impossibilidade de qualquer fração da receita auferida a título de custas judiciais não ser destinada exclusivamente ao custeio dos serviços afetos às atividades específicas da Justiça. A divulgação dos montantes de cada tributo arrecadado até o último dia do mês subsequente ao da arrecadação é, aliás, um dever constitucional dos entes federativos (art. 162, caput, da CRFB).

A quinta premissa está relacionada à natureza de taxa de serviço adjudicatório (STF, ADI 5.612, Rel. Min. Edson Fachin; HARADA, 2017, p. 355-356) da remuneração dos serviços públicos específicos e divisíveis prestados diretamente pelos servidores lotados no Poder Judiciário (DINAMARCO \& LOPES, 2016, 33, 77-78, 97). No Quadro n. 2.A infra está listada toda a disciplina legal dos tributos (taxas e seus eventuais adicionais) instituídos pela União e pelos Estados-membros, cobrados em razão da prestação direta, efetiva ou potencial, de serviços públicos específicos e divisíveis por servidores públicos lotados nos órgãos jurisdicionais do Poder Judiciário.

Quadro n. 2.A - Relação dos atos normativos instituidores de exações obrigatórias cobradas em razão da prestação de serviços judiciários judiciais

\begin{tabular}{|c|c|c|c|}
\hline \multicolumn{2}{|r|}{ Ente Federativo } & Ato Normativo & Nome do Tributo \\
\hline \multirow[t]{10}{*}{ União } & $\begin{array}{l}\text { Supremo Tribunal } \\
\text { Federal (STF) }\end{array}$ & Resolução n. 662/2020/STF & Custas \\
\hline & $\begin{array}{l}\text { Superior Tribunal de } \\
\text { Justiça (STJ) }\end{array}$ & Lei n. 11.636/2007 & Custas \\
\hline & Justiça Federal & Lei n. 9.289/1996 & Custas \\
\hline & Justiça do Trabalho & $\begin{array}{l}\text { Art. } 702, \mathrm{I}, g ; 711, f ; \text { e } 788 \text { a } 790-\mathrm{A} \text { do Anexo ao } \\
\text { Decreto-Lei n. 5.452/1943 (CLT) }\end{array}$ & Custas \\
\hline & Justiça Eleitoral & $\begin{array}{l}\text { Art. } 367 \text {, VIII e } \S 4^{\circ} \text {; e } 373 \text {, parágrafo único, da Lei } \\
\text { n. } 4.737 / 1965^{103}\end{array}$ & Custas \\
\hline & Justiça Militar & Não há. ${ }^{104}$ & Não há. \\
\hline & \multirow{4}{*}{$\begin{array}{l}\text { Justiça do Distrito } \\
\text { Federal e Territórios }\end{array}$} & Decreto-Lei n. $115 / 1967^{105}$ & Custas \\
\hline & & Art. 20 do Decreto-Lei n. 115/1967 & \multirow[t]{2}{*}{ Taxa Judiciária } \\
\hline & & Art. $1^{\circ}$, parágrafo único, da Lei n. $6.811 / 1980$ & \\
\hline & & Tabela B do Anexo do Decreto-Lei n. 115/1967 & $\begin{array}{l}\text { Custas devidas à Ordem dos } \\
\text { Advogados do Brasil - } \\
\text { Seção do Distrito Federal }\end{array}$ \\
\hline
\end{tabular}

\footnotetext{
103 Código Eleitoral.

${ }^{104}$ Conforme artigo 712 do Decreto-Lei n. 1.002/1969 (CPPM).

${ }^{105}$ Regimento de Custas da Justiça do Distrito Federal.
} 


\begin{tabular}{|c|c|c|}
\hline \multicolumn{3}{|c|}{ Região Norte } \\
\hline \multirow[t]{2}{*}{ Acre (AC) } & \multirow[t]{2}{*}{ Lei n. $1.422 / 2001 / \mathrm{AC}^{106}$} & Taxa Judiciária \\
\hline & & Taxa de Diligências \\
\hline \multirow[t]{2}{*}{ Amapá (AP) } & Lei n. 953/2005/AP & Taxa Judiciária \\
\hline & $\begin{array}{l}\text { Art. } 1^{\circ}, \text { caput e } \$ \S 1^{\circ}, 3^{\circ} \text { e } 4^{\circ} ; 2^{\circ} \text {, I; e } 3^{\circ} \text { a } 41 \text { da Lei } \\
\text { n. } 1.436 / 2009 / \mathrm{AP}\end{array}$ & Custas Judiciais \\
\hline \multirow[t]{3}{*}{ Amazonas (AM) } & $\begin{array}{l}\text { Artigos } 1^{\circ} ; 2^{\circ} ; 7^{\circ} ; 9^{\circ}, a ; \text { e } 11 \text { a } 14 \text { da Lei } n . \\
2.429 / 1996 / \mathrm{AM}^{107}\end{array}$ & Custas Judiciais \\
\hline & $\begin{array}{l}\text { Art. } 6^{\circ} ; 7^{\circ}, \text { caput } ; 9^{\circ}, b ; 13 ; \text { e } 14 \text { da Lei n. } \\
2.429 / 1996 / \mathrm{AM}^{108}\end{array}$ & \multirow[t]{2}{*}{ Taxa Judiciária } \\
\hline & $\begin{array}{l}\text { Art. 158, II; } 170 \text { e } 171 \text { da Lei Complementar n. } \\
\text { 19/1997/AM }^{109}\end{array}$ & \\
\hline Pará (PA) & Lei n. 8.328/2015/PA ${ }^{110}$ & Custas Processuais \\
\hline Rondônia (RO) & Lei n. 3.896/2016/RO & Custas Judiciais \\
\hline \multirow[t]{2}{*}{ Roraima (RR) } & $\begin{array}{l}\text { Art. 123, II; 127; 132; 133; 134, II; 135, I; e } 136 \text { da } \\
\text { Lei n. 59/1993/RR }\end{array}$ & Taxa Judiciária \\
\hline & Art. $1^{\circ}$ a 19 do Lei n. $1.157 / 2016 / \mathrm{RR}$ & Custas Judiciais \\
\hline \multirow[t]{2}{*}{ Tocantins (TO) } & Art. $1^{\circ}$ a $7^{\circ}$; e 20 a 26 da Lei n. $1.286 / 2001 /$ TO & Custas Judiciais \\
\hline & $\begin{array}{l}\text { Art. 20, II, } a \text {; } \\
1.287 / 2001 / \mathrm{TO}^{111}\end{array}$ & Taxa Judiciária \\
\hline \multicolumn{3}{|c|}{ Região Nordeste } \\
\hline \multirow[t]{2}{*}{ Alagoas (AL) } & Lei n. 3.185/1971/AL ${ }^{112}$ & Custas Judiciais \\
\hline & Art. 392 a 404 da Lei n. 4.418/1982/AL ${ }^{113}$ & Taxa Judiciária \\
\hline Bahia (BA) & $\begin{array}{l}\text { Art. } 1^{\circ}, \text { II; } 3^{\circ} ; 5^{\circ} \text { a } 25 ; 28 \text {; e } 29 \text { da Lei } n \text {. } \\
\text { 12.373/2011/BA }\end{array}$ & $\begin{array}{lll}\text { Taxa de Prestação } & \text { de } \\
\text { Serviços no âmbito } & \text { do } \\
\text { Poder Judiciário } & \end{array}$ \\
\hline \multirow[t]{4}{*}{ Ceará (CE) } & Lei n. 9.771/1973/CE ${ }^{114}$ & Taxa Judiciária \\
\hline & $\begin{array}{l}\text { Art. } 3^{\circ} \text { da Lei n. } 12.642 / 1996 \text {, com redação dada } \\
\text { pelo art. } 1^{\circ} \text { da Lei n. } 14.247 / 2008 / C E\end{array}$ & FAADEP \\
\hline & $\begin{array}{l}\text { Art. } 1^{\circ} ; 2^{\circ} \text {, II e } \S \S 1^{\circ} \text { a } 3^{\circ} \text {; e } 3^{\circ} \text { a } 8^{\circ} \text { da Lei } n \text {. } \\
16.131 / 2016 / \mathrm{CE}\end{array}$ & FRMMP/CE \\
\hline & Lei n. 16.132/2016/CE & Custas Processuais \\
\hline \multirow[t]{2}{*}{ Maranhão (MA) } & Art. $4^{\circ}$, II; e 132 a 143 da Lei n. 7.799/2002/MA & Taxa Judiciária \\
\hline & $\begin{array}{l}\text { Art. } 1^{\circ} \text { e } 2^{\circ} ; 4^{\circ} \text { a } 7^{\circ} ; 12 ; 14 \text { a } 28, \text { caput; } 29 \text { a } 35 ; \text { e } \\
37 \text { a } 40 \text { da Lei n. 9.109/2009/MA }\end{array}$ & Custas \\
\hline
\end{tabular}

\footnotetext{
${ }^{106}$ Regimento de Custas do Poder Judiciário do Estado do Acre.

${ }^{107}$ Regimento de Custas Judiciárias do Estado do Amazonas.

${ }^{108}$ Regimento de Custas Judiciárias do Estado do Amazonas.

${ }^{109}$ Código Tributário do Estado do Amazonas.

${ }^{110}$ Regimento de Custas e outras despesas processuaisno âmbito do Poder Judiciário do Estado do Pará.

${ }^{111}$ Código Tributário do Estado do Tocantins.

${ }^{112}$ Código de Custas Judiciais.

${ }^{113}$ Código Tributário do Estado de Alagoas.

${ }^{114}$ Regimento de Custas e Emolumentos da Justiça do Ceará.
} 


\begin{tabular}{|c|c|c|}
\hline \multirow[t]{2}{*}{ Paraíba (PB) } & Lei n. 5.672/1992/PB ${ }^{115}$ & Custas Judiciais \\
\hline & Lei n. 6.682/1998/PB & Taxa Judiciária \\
\hline \multirow[t]{2}{*}{ Pernambuco (PE) } & Lei n. 10.852/1992/PE & Taxa Judiciária \\
\hline & $\begin{array}{l}\text { Art. } 1^{\circ} \text { a } 21 ; 24 \text { a } 26 \text {; e } 33 \text { a } 38 \text { da Lei n. } \\
11.404 / 1996 / \mathrm{PE}\end{array}$ & Custas \\
\hline \multirow[t]{2}{*}{ Piauí (PI) } & $\begin{array}{l}\text { Art. } 1^{\circ} ; 2^{\circ} ; 3^{\circ} \text {, I a III; } 4^{\circ}, \text { II; } 7^{\circ} ; 8^{\circ} ; 9^{\circ} \text {, I e } \S 1^{\circ}, 11 \text { a } \\
\text { 13; e Tabela III da Lei n. } 4.254 / 1988 / \text { PI }\end{array}$ & Taxas Judiciárias \\
\hline & $\begin{array}{l}\text { Art. } 1^{\circ} \text { a } 15 ; 33 ; 34 ; \text { e } 36 \text { a } 38 \text { da Lei n. } \\
6.920 / 2016 / \text { PI }\end{array}$ & Custas Judiciais \\
\hline Rio Grande do Norte (RN) & $\begin{array}{l}\text { Art. } 1^{\circ} ; 4^{\circ} \text { a } 11 ; 38 ; 40 ; \text { e } 48 \text { a } 51 \text { da Lei n. } \\
9.278 / 2009 / \mathrm{RN}\end{array}$ & Custas Judiciais \\
\hline \multirow[t]{2}{*}{ Sergipe (SE) } & Art. $4^{\circ}$ a $9^{\circ}$ da Lei n. 3.657/1995/SE & Taxa Judiciária \\
\hline & Art. $1^{\circ}$ a $7^{\circ}$ da Lei n. $8.345 / 2017 / \mathrm{SE}$ & Custas Judiciais \\
\hline \multicolumn{3}{|c|}{ Região Centro-Oeste } \\
\hline \multirow[t]{2}{*}{ Goiás (GO) } & $\begin{array}{l}\text { Art. 112, II e parágrafo único, I; 113, I; } 114 \text { a 114- } \\
\text { B; e 116, I, da Lei n. 11.651/1991/GO } 116\end{array}$ & Taxa Judiciária \\
\hline & Lei n. $14.376 / 2002 / \mathrm{GO}^{117}$ & Custas.e Emolumentos \\
\hline \multirow[t]{3}{*}{ Mato Grosso (MT) } & $\begin{array}{l}\text { Art. 17, parágrafo único; e } 104 \text { a } 110 \text { da Lei n. } \\
\text { 4.547/1982/MT }\end{array}$ & \multirow[t]{2}{*}{ Taxa Judiciária } \\
\hline & Lei Complementar n. 261/2006/MT & \\
\hline & $\begin{array}{l}\text { Lei n. } 7.603 / 2001 \text {, com redação dada pela Lei n. } \\
11.077 / 2020 \mathrm{MT}\end{array}$ & Custas \\
\hline \multirow[t]{3}{*}{ Mato Grosso do Sul (MS) } & Lei n. 3.779/2009/MS ${ }^{118}$ & Taxa Judiciária \\
\hline & \multirow[t]{2}{*}{ Art. $1^{\circ}$, I, da Lei Complementar n. 179/2013/MS } & FUNDE-PGE \\
\hline & & FUNADEP \\
\hline \multicolumn{3}{|c|}{ Região Sudeste } \\
\hline Espírito Santo (ES) & Lei n. 9.974/2013/ES ${ }^{119}$ & Custas \\
\hline \multirow[t]{2}{*}{ Minas Gerais (MG) } & Art. $4^{\circ}$, IV; e 99 a 112-A da Lei n. 6.763/1975/MG & Taxa Judiciária \\
\hline & Lei n. 14.939/2003/MG & Custas \\
\hline \multirow[t]{6}{*}{ Rio de Janeiro (RJ) } & Art. 112 a 146 do Decreto-Lei n. 5/1975/RJ ${ }^{120}$ & \multirow[t]{2}{*}{ Taxa Judiciária } \\
\hline & Art. 10, inciso X, da Lei n. 3.350/1999/RJ & \\
\hline & $\begin{array}{l}\text { Art. } 1^{\circ} \text { a } 9^{\circ} ; 10, \text { I; } 17 \text { a } 33 ; 48 ; \text { e } 50 \text { da Lei n. } \\
\text { 3.350/1999/RJ }\end{array}$ & Custas Judiciais \\
\hline & $\begin{array}{l}\text { Art. } 4^{\circ} \text {, III, da Lei n. } 4.664 / 2005 / \text { RJ; e art. } 6^{\circ} \text { da Lei } \\
\text { n. } 6.369 / 2012 / \text { RJ }\end{array}$ & FUNDPERJ \\
\hline & $\begin{array}{l}\text { Art. 31, III, da Lei Complementar n. 111/2006/RJ; } \\
\text { e art. } 6^{\circ} \text { da Lei n. } 6.369 / 2012 / \text { RJ }\end{array}$ & FUNPERJ \\
\hline & Art. $6^{\circ}$ da Lei n. 6.369/2012/RJ & CAARJ/IAB \\
\hline
\end{tabular}

\footnotetext{
${ }^{115}$ Regimento de Custas Judiciais e Emolumentos Extrajudiciais.

${ }^{116}$ Código Tributário do Estado de Goiás.

${ }^{117}$ Regimento de Custas e Emolumentos da Justiça do Estado de Goiás.

${ }^{118}$ Regimento de Custas Judiciais do Estado do Mato Grosso do Sul.

${ }^{119}$ Regimento de Custas.

${ }^{120}$ Código Tributário do Estado do Rio de Janeiro.
} 


\begin{tabular}{|l|l|l|}
\hline São Paulo (SP) & Lei n. 11.608/2003/SP & Taxa Judiciária \\
\hline \multicolumn{2}{|c|}{ Região Sul } \\
\hline \multirow{2}{*}{ Paraná (PR) } & Decreto n. 962/1932/PR & Taxa Judiciária \\
\cline { 2 - 3 } & Lei n. 6.149/1970/PR & Custas \\
\hline Rio Grande do Sul (RS) & Lei n. 14.634/2014/RS & $\begin{array}{l}\text { Taxa Única de Serviços } \\
\text { Judiciais }\end{array}$ \\
\hline Santa Catarina (SC) & Lei n. 17.654/2018/SC & Taxa de Serviços Judiciais \\
\hline
\end{tabular}

A sexta premissa refere-se à classificação jurídico-financeira das despesas que são compatíveis com a teleologia da regra do art. $98, \S 2^{\circ}$, da CRFB. Nos termos da Lei Geral de Finanças Públicas, o custeio dos serviços afetos às atividades específicas da Justiça abrangeria a manutenção de serviços anteriormente criados, inclusive as destinadas a atender a obras de conservação e adaptação de bens imóveis, subdividindo-se em despesas com pessoal civil, material de consumo, serviços de terceiros e encargos diversos (art. 12, $\S 1^{\text {o }}$; e 13 da Lei n. 4.320/1964). A maioria dos fundos especiais de reaparelhamento e modernização do Poder Judiciário e das Funções Essenciais à Justiça veda, contudo, a destinação de suas receitas ao pagamento de despesas de pessoal.

Por fim, a sétima premissa esclarece que, desde que se respeite o caráter privativo da iniciativa de lei pelo Poder Judiciário, parcela da receita das custas judiciais pode ser repartida com o Ministério Público, a Advocacia Pública, a Advocacia e a Defensoria Pública. Essas instituições são essenciais à Justiça, porque são as responsáveis por provocar o Estado a prestar jurisdição (MENDES et al., 2009, p. 1.037).

\section{RESULTADOS OBTIDOS}

Os resultados obtidos foram organizados no Quando 3.A infra. Para cada um dos 27 entes federativos pesquisados foi atribuída uma linha dividida em quatro colunas. Os 26 Estados-membros são agrupados conforme a divisão do território brasileiro em cinco regiões, na seguinte ordem: Norte (7), Nordeste (9), Centro-Oeste (3), Sudeste (4) e Sul (3). A primeira coluna identifica o sujeito ativo da relação jurídico-tributária, ou seja, o ente federativo que institui e cobra exações pela prestação direta, efetiva ou potencial, de serviços judiciários judiciais. No caso de Estado-membro, sua sigla é indicada a fim de facilitar a compreensão das notas de rodapé. A segunda coluna identifica a instituição pública ou a

\footnotetext{
${ }^{121}$ Regime de Custas dos Atos Judiciais.
} 
entidade privada destinatária de percentual da receita auferida a título de taxas de prestação direta de serviços por servidores do Poder Judiciário no âmbito judicial e/ou de adicionais sobre essa receita derivada. No caso do Poder Judiciário, do Ministério Público, da Advocacia Pública, da Advocacia e da Defensoria Pública, essa segunda coluna subdivide-se de modo a identificar o fundo especial a que a verba está vinculada. Para cada fundo foi atribuída uma nota de rodapé que indica o ato normativo primário de regência. A terceira e a quarta colunas indicam, respectivamente, o percentual vinculado da receita auferida a títulos dessas taxas de serviços e os eventuais adicionais, com a fundamentação legal em nota de rodapé.

Quadro n. 3.A - A repartição da receita das taxas pela prestação direta de serviços por servidores do Poder Judiciário no âmbito judicial e de seus adicionais

\begin{tabular}{|c|c|c|c|c|}
\hline \multirow{2}{*}{$\begin{array}{l}\text { Sujeito Ativo } \\
\text { União }\end{array}$} & \multicolumn{2}{|r|}{ Instituição } & \multirow{2}{*}{$\frac{\text { Percentual }}{A^{123}}$} & \multirow{2}{*}{$\frac{\text { Adicional }}{\mathrm{X}}$} \\
\hline & \multirow{2}{*}{$\begin{array}{l}\text { Poder Judiciário } \\
\text { do Distrito Federal } \\
\text { e Territórios }\end{array}$} & \multirow{2}{*}{$\begin{array}{l}\text { Programa de Modernização e } \\
\text { Aperfeiçoamento da Justiça do } \\
\text { Distrito Federal e dos Territórios de } \\
\text { Primeiro e Segundo Graus } \\
\text { (PROJUS) }\end{array}$} & & \\
\hline & & & $100 \%^{124}$ & \\
\hline & \multirow[t]{2}{*}{ Advocacia } & \multirow{2}{*}{$\begin{array}{l}\text { Ordem dos Advogados do Brasil - } \\
\text { Seção Distrito Federal (OAB-DF) }\end{array}$} & $B^{125}$ & $\mathbf{A}$ \\
\hline & & & $100 \%^{126}$ & $10 \%{ }^{127}$ \\
\hline \multicolumn{5}{|c|}{ Região Norte } \\
\hline \multirow[t]{2}{*}{ Acre (AC) } & \multirow[t]{2}{*}{ Poder Judiciário } & $\begin{array}{l}\text { Fundo Especial do Poder Judiciário } \\
\text { (FUNEJ) }^{128}\end{array}$ & $95 \%^{129}$ & $\mathrm{X}$ \\
\hline & & $\begin{array}{l}\text { Fundo Estadual de Segurança dos } \\
\text { Magistrados (FUNSEG) }\end{array}$ & $5 \%^{131}$ & $\mathrm{X}$ \\
\hline \multirow[t]{2}{*}{ Amapá (AP) } & \multirow[t]{2}{*}{ Poder Judiciário } & 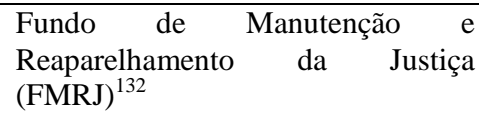 & $79,49 \%^{133}$ & $\mathrm{X}$ \\
\hline & & $\begin{array}{l}\text { Fundo de Apoio aos Juizados } \\
\text { Especiais da Infância e da Juventude } \\
\text { das Comarcas do Estado do Amapá } \\
(\text { FAJIJ) }\end{array}$ & $4,18 \%{ }^{135}$ & $\mathrm{X}$ \\
\hline
\end{tabular}

${ }^{122}$ Vide art. 83 da Lei n. 11.697/2008.

${ }^{123}$ Custas.

${ }^{124}$ Art. 83 , § $1^{\circ}$, I, da Lei n. $11.697 / 2008$, combinado com art. $6^{\circ}$, I, $a$, da Lei n. 13.500/2017.

${ }^{125}$ Taxa Judiciária.

${ }^{126}$ Art. $1^{\circ}$, caput, da Lei n. 6.811/1980.

127 Tabela B do Anexo do Decreto-Lei n. 115/1967.

${ }^{128}$ Art. 19 e 21 a 24 da Lei n. 1.422/2001/AC, com redação dada pela Lei n. 2.533/2011/AC.

${ }^{129}$ Art. 17 , I e $\$ \S 1^{\circ}$ e $2^{\circ}$, e $19, \S 2^{\circ}$, da Lei n. $1.422 / 2001 /$ AC.

${ }^{130}$ Vide art. 19 e 21 a 24 da Lei n. 1.422/2001/AC, com redação dada pela Lei n. 2.533/2011/AC.

131 Art. 17 , I e $\S \S 1^{\circ}$ e $2^{\circ}$, e $20, \S 1^{\circ}$, da Lei n. 1.422/2001/AC, com redação dada pelo art. $1^{\circ}$ da Lei $n$. 2.533/2011/AC.

${ }^{132}$ Vide art. 77 do Decreto (N) n. 69/1991/AP, e Decreto (N.) n. 158/1991/AP.

${ }^{133}$ Art. 11, I, da Lei n. 2.386/2018/AP.

${ }^{134}$ Vide art. 13, II e parágrafo único, da Lei n. 953/2005/AP.

${ }^{135}$ Art. 11, II, da Lei n. 2.386/2018/AP. 


\begin{tabular}{|c|c|c|c|c|}
\hline & Ministério Público & 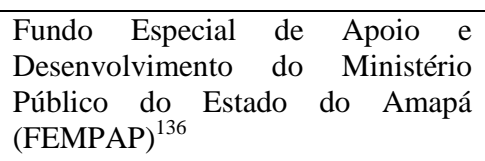 & $8,17 \%$ & $\mathrm{X}$ \\
\hline & $\begin{array}{l}\text { Defensoria } \\
\text { Pública }\end{array}$ & $\begin{array}{lccc}\text { Fundo } & \text { Especial } & \text { da } & \text { Defensoria } \\
\text { Pública } & (\text { FEDP) }\end{array}$ & $8.17 \%^{139}$ & $\mathrm{X}$ \\
\hline $\begin{array}{l}\text { Amazonas } \\
\text { (AM) }\end{array}$ & Poder Judiciário & $\begin{array}{l}\text { Fundo de Modernização e } \\
\text { Reaparelhamento do Poder } \\
\text { Judiciário Estadual (FUNJEAM) }\end{array}$ & $100 \%{ }^{141}$ & $\mathrm{X}$ \\
\hline Pará (PA) & Poder Judiciário & $\begin{array}{l}\text { Fundo de Reaparelhamento do } \\
\text { Judiciário (FRJ) }\end{array}$ & $100 \%^{143}$ & $\mathrm{X}$ \\
\hline \multirow[t]{2}{*}{$\begin{array}{l}\text { Rondônia } \\
\text { (RO) }\end{array}$} & Poder Judiciário & $\begin{array}{l}\text { Fundo de Informatização, } \\
\text { Edificação e Aperfeiçoamento dos } \\
\text { Serviços Judiciários (FUJU) }\end{array}$ & $100 \%{ }^{145}$ & $\mathrm{X}$ \\
\hline & Ministério Público & $\begin{array}{l}\text { Fundo de } \\
\text { Institucional do Ministério Público } \\
\text { do Estado de Rondônia } \\
\text { (FUNDIMPER) }\end{array}$ & A definir. ${ }^{147}$ & $\mathrm{X}$ \\
\hline Roraima (RR) & Poder Judiciário & $\begin{array}{l}\text { Fundo Especial do Poder Judiciário } \\
\text { de Roraima (FUNDEJURR) }{ }^{148}\end{array}$ & $100 \%^{149}$ & $\mathrm{X}$ \\
\hline \multirow[t]{2}{*}{$\begin{array}{l}\text { Tocantins } \\
\text { (TO) }\end{array}$} & Poder Judiciário & $\begin{array}{l}\text { Fundo Especial de Modernização e } \\
\text { Aprimoramento do Poder Judiciário } \\
\text { (FUNJURIS-TO) }^{150}\end{array}$ & $98 \%{ }^{151}$ & $\mathrm{X}$ \\
\hline & & $\begin{array}{l}\text { Fundo Estadual de Segurança dos } \\
\text { Magistrados (FUNSEG) }\end{array}$ & $2 \%{ }^{153}$ & $\mathrm{X}$ \\
\hline \multicolumn{5}{|c|}{ Região Nordeste } \\
\hline \multirow[t]{2}{*}{ Alagoas (AL) } & Poder Judiciário & $\begin{array}{l}\text { Fundo Especial de Modernizaçãa do } \\
\text { Poder Judiciário (FUNJURIS) }{ }^{154}\end{array}$ & $97 \% \%^{155}$ & $\mathrm{X}$ \\
\hline & & $\begin{array}{l}\text { Fundo Especial da Escola Superior } \\
\text { da Magistratura do Estado de } \\
\text { Alagoas (FUNDESMAL) }\end{array}$ & $1 \%{ }^{157}$ & $\mathrm{X}$ \\
\hline
\end{tabular}

${ }^{136}$ Vide art. $7^{\circ}$ a 15 da Lei n. 1.847/2014/AP.

${ }^{137}$ Art. 11, III, da Lei n. 2.386/2018/AP (proposição do Poder Judiciário), com redação dada pelo art. $1^{\circ}$ da Lei n. 2.492/2020/AP (proposição do Poder Executivo).

${ }^{138}$ Vide art. 129 a 138 da Lei Complementar n. 86/2014/AP.

${ }^{139}$ Art. 11, IV, da Lei n. 2.386/2018/AP (proposição do Poder Judiciário), com redação dada pelo art. $1^{\circ}$ da Lei n. 2.492/2020/AP (proposição do Poder Executivo).

${ }^{140}$ Vide Lei n. 4.108/2014/AM.

${ }^{141}$ Art. $3^{\circ}$, VII, $c$ e $d$, da Lei n. 4.108/2014/AM.

${ }^{142}$ Vide Lei Complementar n. 21/1994/PA.

${ }^{143}$ Art. $3^{\circ}$, II, IV, V e VI, da Lei Complementar n. 21/1994/PA; e art. $1^{\circ}$, § $1^{\circ}$, da Lei n. 8.328/2015/PA.

${ }^{144}$ Vide Lei n. 1.963/2008/RO.

${ }^{145}$ Art. $3^{\circ}$, II e IV, da Lei n. 1.963/2008/RO; e art. 41 da Lei n. 3.896/2016/RO.

${ }^{146}$ Vide Lei Complementar n. 296/2004/RO.

${ }^{147}$ Vide art. $3^{\circ}$, VI, da Lei Complementar n. 296/2004/RO.

${ }^{148}$ Vide Lei n. 297/2001/RO.

${ }^{149}$ Art. $3^{\circ}$, I, da Lei n. 297/2001/RR; e art. $4^{\circ}$, caput, da Lei n. 1.167/2016/RR.

${ }^{150}$ Vide Lei n. 954/1998/TO.

${ }^{151}$ Art. $2^{\circ}$, I, da Lei n. 954/1998/TO combinado com art. $3^{\circ}$, I, da Lei n. 3.586/2019/TO.

${ }^{152}$ Vide Lei n. 3.586/2019/TO.

${ }^{153}$ Art. $3^{\circ}$, I, da Lei n. 3.586/2019/TO.

${ }^{154}$ Vide Lei n. 5.887/1996/AL.

${ }^{155}$ Art. $1^{\circ}$, § $1^{\circ}$, I, da Lei n. 5.887/1996/AL.

${ }^{156}$ Vide Lei n. 6.687/2006/AL.

${ }^{157}$ Art. $110, \S 3^{\circ}$, e 259 da Lei n. 6.564/2005/AL, e art. $5^{\circ}$, III, da Lei n. 6.687/2006/AL. 


\begin{tabular}{|c|c|c|c|c|}
\hline & & $\begin{array}{l}\text { Fundo Estadual de Segurança dos } \\
\text { Magistrados (FUNSEG) }\end{array}$ & $2 \%{ }^{159}$ & $\mathrm{X}$ \\
\hline \multirow[t]{2}{*}{ Bahia (BA) } & \multirow[t]{2}{*}{ Poder Judiciário } & $\begin{array}{l}\text { Fundo de Aparelhamento Judiciário } \\
(\text { FAJ })^{160}\end{array}$ & $99,5 \%^{161}$ & $\mathrm{X}$ \\
\hline & & $\begin{array}{l}\text { Fundo Estadual de Segurança dos } \\
\text { Magistrados (FUNSEG-BA) }{ }^{162}\end{array}$ & $0,5 \%^{163}$ & $\mathrm{X}$ \\
\hline \multirow[t]{4}{*}{ Ceará (CE) } & \multirow[t]{2}{*}{ Poder Judiciário } & $\begin{array}{l}\text { Fundo Especial de Reaparelhamento } \\
\text { e Modernização do Poder Judiciário } \\
\text { (FERMOJU) }^{164}\end{array}$ & $97 \%^{165}$ & $\mathrm{X}$ \\
\hline & & $\begin{array}{l}\text { Fundo Estadual de Segurança dos } \\
\text { Magistrados (FUNSEG-JE) }\end{array}$ & $3 \%^{167}$ & $\mathrm{X}$ \\
\hline & Ministério Público & $\begin{array}{l}\text { Fundo de } \text { Reaparelhamento e } \\
\text { Modernização do Ministério Público } \\
\text { do Estado do Ceá } \\
(\text { FRMMP/CE) })^{168}\end{array}$ & $\mathrm{X}$ & $15 \%^{169}$ \\
\hline & $\begin{array}{l}\text { Defensoria } \\
\text { Pública }\end{array}$ & $\begin{array}{l}\text { Fundo de Apoio e Aparelhamento } \\
\text { da Defensoria Pública-Geral do } \\
\text { Estado do Ceará (FAADEP) }\end{array}$ & $\mathrm{X}$ & $12 \%^{171}$ \\
\hline \multirow[t]{2}{*}{$\begin{array}{l}\text { Maranhão } \\
\text { (MA) }\end{array}$} & \multirow[t]{2}{*}{ Poder Judiciário } & $\begin{array}{l}\text { Fundo Especial de Modernização e } \\
\text { Reaparelhamento } \\
(\text { FERJ })^{172}\end{array}$ & $97 \%^{173}$ & $X$ \\
\hline & & $\begin{array}{llr}\text { Fundo de } & \text { Segurança dos } \\
\text { Magistrados } & \text { do } & \text { Maranhão } \\
(\text { FUNSEG-JE) } & & \end{array}$ & $3 \%^{175}$ & $\mathrm{X}$ \\
\hline \multirow[t]{2}{*}{ Paraíba (PB) } & \multirow[t]{2}{*}{ Poder Judiciário } & $\begin{array}{l}\text { Fundo Especial do Poder Judiciário } \\
\text { (FEPJ) })^{176}\end{array}$ & $90 \% \%^{177}$ & $\mathrm{X}$ \\
\hline & & $\begin{array}{l}\text { Fundo de Apoio ao Registro das } \\
\text { Pessoas Naturais (FARPEN) }{ }^{178}\end{array}$ & $2 \%{ }^{179}$ & $\mathrm{X}$ \\
\hline
\end{tabular}

${ }^{158}$ Vide Lei n. 7.910/2017/AL.

${ }^{159}$ Art. 3o, I, da Lei n. 7.910/2017/AL.

${ }^{160}$ Vide art. 10 a 14 da Lei n. 11.918/2010/BA.

${ }^{161}$ Art. 12, II, da Lei n. 11.918/2010/BA combinado com art. 4º I, da Lei n. 13.971/2018/BA.

${ }^{162}$ Vide Lei n. 13.971/2018/BA.

${ }^{163}$ Art. $4^{\circ}$, I, da Lei n. 13.971/2018/BA.

164 Vide Lei n. 14.605/2010/CE.

${ }^{165}$ Art. $3^{\circ}$, I, da Lei n. 14.605/2010/CE, combinado com art. 4º I, da Lei n. 15.145/2012/CE.

${ }^{166}$ Vide Lei n. 15.145/2012/CE.

167 Art. $4^{\circ}$, I, da Lei n. 15.145/2012/CE combinado com art. $3^{\circ}$ do Provimento n. 25/2012/PRES/TJCE, com redação dada pelo art. $1^{\circ}$ do Provimento n. 12/2017/PRES/TJCE.

${ }^{168}$ Vide Lei n. 15.912/2015/CE e Lei n. 16.131/2016/CE.

${ }^{169}$ Art. $2^{\circ}$, II, $b$, da Lei n. 16.131/2016/CE (proposição do Poder Judiciário).

${ }^{170}$ Vide Lei n. 12.642/1996/CE, com redação dada pela Lei n. 14.247/2008/CE, e Lei n. 13.180/2001/CE.

${ }^{171}$ Art. $3^{\circ}$ da Lei n. 12.642/1996/CE, com redação dada pelo art. $1^{\circ}$ da Lei n. 14.247/2008/CE (proposição do Poder Judiciário).

${ }^{172}$ Vide Lei Complementar n. 48/2000/MA.

173 Art. $3^{\circ}$, II e III, da Lei Complementar n. 48/2000/MA combinado com art. $2^{\text {o }}$ da Lei n. 8.414/2006/MA combinado com art. $1^{\circ}$ do Ato n. 32.015/2015/PRES/TJMA.

${ }^{174}$ Vide Lei Complementar n. 164/2014/MA.

${ }^{175}$ Art. $4^{\text {o }}$, I, da Lei Complementar n. 164/2014/MA combinado com art. $1^{\text {o }}$ do Ato n. 32.015/2015/PRES/TJMA.

176 Vide Lei n. 4.551/1983/PB.

177 Subitem II do item III da Tabela B da Lei n. 5.672/1992/PB, com redação dada pelo art. $4^{\circ}$ da Lei n. 8.071/2006/PB, combinado com art. $3^{\circ}$ da Lei n. 9.930/2012/PB.

${ }^{178}$ Vide Lei n. 7.410/2003/PB.

${ }^{179}$ Subitem II do item III da Tabela B da Lei n. 5.672/1992/PB, com redação dada pelo art. $4^{\circ}$ da Lei n. 8.071/2006/PB. 


\begin{tabular}{|c|c|c|c|c|}
\hline & Ministério Público & $\begin{array}{l}\text { Fundo Especial do Ministério } \\
\text { Público (FEMPE) }\end{array}$ & $8 \%{ }^{181}$ & $\mathrm{X}$ \\
\hline \multirow[t]{2}{*}{$\begin{array}{l}\text { Pernambuco } \\
\text { (PE) }\end{array}$} & Poder Judiciário & $\begin{array}{l}\text { Fundo Especial de Reaparelhamento } \\
\text { e Modernização do Poder Judiciário } \\
\text { do Estado de Pernambuco (FERM- } \\
\text { PJPE) }\end{array}$ & $100 \%^{183}$ & $\mathrm{X}$ \\
\hline & Ministério Público & $\begin{array}{l}\text { Fundo de Desenvolvimento } \\
\text { Institucional do Ministério Público } \\
\text { de Pernambuco (FDIMPPE) }\end{array}$ & A definir. ${ }^{185}$ & $\mathrm{X}$ \\
\hline Piauí (PI) & Poder Judiciário & $\begin{array}{l}\text { Fundo Especial de Reaparelhamento } \\
\text { e Modernização do Poder Judiciário } \\
\text { do } \quad \text { Estado } \\
\text { (FERMOJUPI) })^{186}\end{array}$ & $100 \%{ }^{187}$ & $\mathrm{X}$ \\
\hline \multirow[t]{3}{*}{$\begin{array}{l}\text { Rio Grande } \\
\text { do Norte (RN) }\end{array}$} & Poder Judiciário & $\begin{array}{l}\text { Fundo de Desenvolvimento da } \\
\text { Justiça do Poder Judiciário do Rio } \\
\text { Grande do Norte (FDJ) }\end{array}$ & $98 \%{ }^{189}$ & $\mathrm{X}$ \\
\hline & & $\begin{array}{l}\text { Fundo Estadual de Segurança dos } \\
\text { Magistrados (FUNSEG) }\end{array}$ & $2 \% 191$ & $\mathrm{X}$ \\
\hline & Ministério Público & $\begin{array}{l}\text { Fundo de Reaparelhamento do } \\
\text { Ministério Público (FRMP) }\end{array}$ & A definir. ${ }^{193}$ & $\mathrm{X}$ \\
\hline Sergipe (SE) & Poder Judiciário & $\begin{array}{l}\text { Fundo Especial de Recursos e de } \\
\text { Despesas do Tribunal de Justiça do } \\
\text { Estado de Sergipe (FERD) }\end{array}$ & $100 \%{ }^{195}$ & $\mathrm{X}$ \\
\hline \multicolumn{5}{|c|}{ Região Centro-Oeste } \\
\hline Goiás (GO) & Poder Judiciário & $\begin{array}{l}\text { Fundo Especial de Reaparelhamento } \\
\text { e Modernização do Poder Judiciário } \\
\text { (FUNDES-PJ) }^{196}\end{array}$ & $100 \%{ }^{197}$ & $\mathrm{X}$ \\
\hline $\begin{array}{ll}\text { Mato } & \text { Grosso } \\
\text { (MT) } & \end{array}$ & Poder Judiciário & $\begin{array}{l}\text { Fundo de Apoio ao Judiciário } \\
\text { (FUNAJURIS) })^{198}\end{array}$ & $100 \%^{199}$ & $\mathrm{X}$ \\
\hline $\begin{array}{l}\text { Mato Grosso } \\
\text { do Sul (MS) }\end{array}$ & Poder Judiciário & $\begin{array}{lll}\text { Fundo Especial } & \text { para } & \text { o } \\
\text { Desenvolvimento } & \text { e } & \text { o } \\
\text { Aperfeiçoamento das } & \text { Atividades }\end{array}$ & $100 \%{ }^{201}$ & $\mathrm{X}$ \\
\hline
\end{tabular}

${ }^{180}$ Vide Lei n. 5.508/1991/PB, e art. $2^{\circ}$, $\S 4^{\circ}$, da Lei n. 8.102/2006/PB, com redação dada pelo art. $1^{\circ}$ da Lei n. $11.109 / 2018 / \mathrm{PB}$.

${ }^{181}$ Art. $3^{\circ}, a$, da Lei n. 5.508/1991/PB; e art. $3^{\circ}$ da Lei n. 9.930/2012/PB (proposição do Poder Judiciário).

${ }^{182}$ Vide Lei n. 14.989/2013/PE.

${ }^{183}$ Art. $4^{\circ}$, II, da Lei n. 14.989/2013/PE.

${ }^{184}$ Vide Lei n. 15.996/2017/PE.

${ }^{185}$ Vide art. $3^{\circ}$, XIV, da Lei n. 15.996/2017/PE.

${ }^{186}$ Vide art. $11, \S 7^{\circ}$, da Lei n. 3.716/1979/PI e Lei n. 5.425/2004/PI.

${ }^{187}$ Art. $3^{\circ}$, II a IV, da Lei n. 5.425/2004/PI; e art. $3^{\circ}$ da Lei n. 6.920/2016/PI.

${ }^{188}$ Vide art. $2^{\circ}$ e $3^{\circ}$ da Lei n. 9.278/2009/RN.

${ }^{189}$ Art. $3^{\circ}$, I, da Lei n. 9.278/2009/RN, combinado com art. $4^{\circ}$, I, da Lei n. 9.920/2014/RN.

${ }^{190}$ Vide Lei n. 9.920/2014/RN.

${ }_{191}$ Art. $4^{\circ}$, I, da Lei n. 9.920/2014/RN.

${ }^{192}$ Vide Lei n. 9.419/2010/RN.

${ }^{193}$ Vide art. $3^{\circ}$, I, da Lei n. 9.419/2010/RN.

${ }^{194}$ Vide Lei n. 3.099/1991/SE, e art. $5^{\circ}$ e $6^{\circ}$ da Lei n. 3.657/1995/SE.

${ }^{195}$ Art. $2^{\circ}$, I, da Lei n. 3.099/1991/SE, e art. $5^{\circ}$ da Lei n. 3.657/1995/SE, combinados com art. 3º XVI, da Lei n. $6.257 / 2007 / \mathrm{SE}$.

${ }^{196}$ Vide Lei n. 12.986/1996/GO.

${ }^{197}$ Art. $3^{\circ}$, I e II, da Lei n. 12.986/1996/GO; e art. $3^{\circ}$ da Lei n. 13.111/1997/GO combinado com art. $2^{\circ}$, caput, da Lei n. 20.375/2018/GO.

${ }_{198}$ Vide artigo 302 a 307 da Lei n. 4.964/1985/MT, e artigos $3^{\circ}$ a 12 da Lei n. 8.033/2003/MT.

${ }^{199}$ Art. 303, $a$ e $e$, da Lei n. 4.964/1985/MT. 


\begin{tabular}{|c|c|c|c|c|}
\hline & & $\begin{array}{l}\text { dos Juizados Especiais Cíveis e } \\
\text { Criminais (FUNJECC) }\end{array}$ & & \\
\hline & Advocacia Pública & $\begin{array}{l}\text { Fundo Especial da Procuradoria- } \\
\text { Geral do Estado (FUNDE-PGE) }\end{array}$ & $\mathrm{X}$ & 1 UFERMS $^{203}$ \\
\hline & $\begin{array}{l}\text { Defensoria } \\
\text { Pública }\end{array}$ & $\begin{array}{lcc}\text { Fundo Especial para } & \text { o } \\
\text { Aperfeiçoamento } & \mathrm{e} & \text { o } \\
\text { Desenvolvimento das Atividades da } & \\
\text { Defensoria Pública (FUNADEP) }^{204}\end{array}$ & $\mathrm{X}$ & 1 UFERMS $^{205}$ \\
\hline & & Região Sudeste & & \\
\hline $\begin{array}{l}\text { Espírito Santo } \\
\text { (ES) }\end{array}$ & Poder Judiciário & $\begin{array}{l}\text { Fundo Especial do Poder Judiciário } \\
\text { (FUNEPJ) }\end{array}$ & $100 \%{ }^{207}$ & $\mathrm{X}$ \\
\hline $\begin{array}{l}\text { Minas Gerais } \\
\text { (MG) }\end{array}$ & Poder Judiciário & $\begin{array}{l}\text { Fundo Especial do Poder Judiciário } \\
\text { do Estado de Minas Gerais } \\
(\mathrm{FEPJ})^{208}\end{array}$ & $100 \%{ }^{209}$ & $\mathrm{X}$ \\
\hline Rio de Janeiro & Poder Judiciário & Fundo Especial do Tribunal de & $A^{211}+B^{212}$ & $\mathrm{X}$ \\
\hline & & Justiça (FETJ) $)^{110}$ & $100 \%{ }^{213}$ & \\
\hline & Advocacia Pública & Fundo Especial da Procuradoria & $\mathrm{X}$ & B \\
\hline & & $\begin{array}{l}\text { Geral do Estado do Rio de Janeiro } \\
(\text { FUNPERJ) }\end{array}$ & & $5 \%$ \\
\hline & Advocacia & Caixa de Assistência da Advocacia & $\mathrm{X}$ & B \\
\hline & & $\begin{array}{l}\text { do } \begin{array}{l}\text { Estado } \\
(\text { CAARJ) })^{216}\end{array} \\
(\text { Rio de }\end{array}$ & & $9,3 \%{ }^{217}$ \\
\hline & Defensoria & $\begin{array}{llll}\text { Fundo } & \text { Especial da } & \text { Defensoria }\end{array}$ & $\mathrm{X}$ & B \\
\hline & Pública & $\begin{array}{l}\text { Pública do Estado do Rio de Janeiro } \\
(\text { FUNDPERJ })^{218}\end{array}$ & & $5 \%{ }^{219}$ \\
\hline & Instituto dos Advog & dos Brasileiros (IAB) ${ }^{220}$ & $\mathrm{X}$ & $\mathbf{B}$ \\
\hline & & & & $0,7 \%$ \\
\hline
\end{tabular}

${ }^{201}$ Art. 104, I e II, da Lei n. 1.071/1990/MS.

${ }^{200}$ Vide art. 102 a 108 da Lei n. 1.071/1990/MS.

${ }^{202}$ Vide art. 116, $\S 2^{\circ}$; e 147 a 150 da Lei Complementar n. 95/2001/MS, e Lei Complementar n. 179/2013/MS.

${ }^{203}$ Art. $1^{\circ}$, I, da Lei Complementar n. 179/2013/MS (proposição do Poder Executivo).

204 Vide art. $6^{\circ}$ e $7^{\circ}$ da Lei Complementar n. 111/2005/MS; Lei Complementar n. 179/2013/MS; e Lei Complementar n. 208/2015/MS.

${ }^{205}$ Art. $1^{\circ}$, I, da Lei Complementar n. 179/2013/MS (proposição do Poder Executivo).

${ }^{206}$ Vide Lei Complementar n. 219/2001/ES.

207 Art. $3^{\circ}$, II, da Lei Complementar n. 219/2001/ES.

${ }^{208}$ Vide Lei n. 20.802/2013/MG.

${ }^{209}$ Art. $3^{\circ}$, II e III, da Lei n. 20.802/2013/MG.

${ }^{210}$ Vide Lei n. 2.524/1996/RJ; e art. $8^{\circ}$, caput, 15 e 48 da Lei n. 3.350/1999/RJ.

211 Taxa Judiciária.

${ }^{212}$ Custas Judiciais.

213 Art. $3^{\circ}$, inciso II, da Lei n. 2.524/1996/RJ.

${ }^{214}$ Vide art. 28 a 34 da Lei Complementar n. 111/2006/RJ.

215 Art. 31, III, da Lei Complementar n. 111/2006/RJ (proposição do Poder Executivo), e art. $6^{\circ}$ da Lei n. 6.369/2012/RJ (proposição dos Poderes Executivo e Judiciário).

${ }^{216}$ Vide artigos 44 , inciso IV e parágrafo $4^{\circ} ; 56$, parágrafo $3^{\circ} ; 58$, incisos II a IV e XV; 62; 64, parágrafo $1^{\circ}$; e 76 da Lei n. 8.906/1994 (EAOAB).

${ }^{217}$ Art. $6^{\circ}$ da Lei n. 6.369/2012/RJ (proposição dos Poderes Executivo e Judiciário), combinado com art. 81, I, da Lei n. 1.010/1986/RJ (revogado pelo art. 51 da Lei n. 3.350/1999/RJ).

${ }^{218}$ Vide Lei n. 4.664/2005/RJ.

219 Art. $4^{\circ}$, III, da Lei n. 4.664/2005/RJ (proposição do Poder Executivo), e art. $6^{\circ}$ da Lei n. 6.369/2012/RJ (proposição dos Poderes Executivo e Judiciário).

${ }^{220}$ Vide Decreto Legislativo n. 4.753-A/1923; e art. 85 da Lei n. 8.906/1994 (EAOAB).

${ }^{221}$ Art. $6^{\circ}$ da Lei n. 6.369/2012/RJ (proposição dos Poderes Executivo e Judiciário), combinado com art. 81, II, da Lei n. 1.010/1986/RJ (revogado pelo art. 51 da Lei n. 3.350/1999/RJ). 


\begin{tabular}{|c|c|c|c|c|}
\hline \multirow{4}{*}{$\begin{array}{ll}\text { São } & \text { Paulo } \\
\text { (SP) } & \end{array}$} & \multicolumn{2}{|r|}{$\mathrm{X}$} & $21,67 \%$ & $\mathrm{X}$ \\
\hline & \multirow[t]{2}{*}{ Poder Judiciário } & $\begin{array}{l}\text { Fundo Especial de Despesa do } \\
\text { Tribunal de Justiça (FEDTJ) }\end{array}$ & $60 \% \%^{223}$ & $\mathrm{X}$ \\
\hline & & Diligências & $10 \%{ }^{224}$ & $\mathrm{X}$ \\
\hline & $\begin{array}{l}\text { Defensoria } \\
\text { Pública }\end{array}$ & $\begin{array}{l}\text { Fundo de Assistência Judiciária } \\
(\mathrm{FAJ})^{225}\end{array}$ & $8,33 \%$ & $\mathrm{X}$ \\
\hline \multicolumn{5}{|c|}{ Região Sul } \\
\hline \multirow[t]{4}{*}{ Paraná (PR) } & \multirow[t]{4}{*}{ Poder Judiciário } & \multirow{2}{*}{$\begin{array}{l}\text { Fundo de Reequipamento do Poder } \\
\text { Judiciário (FUNREJUS) }\end{array}$} & $A^{228}+B^{229}+C^{230}$ & \multirow[t]{2}{*}{$\mathrm{X}$} \\
\hline & & & $100 \%{ }^{231}$ & \\
\hline & & \multirow[t]{2}{*}{ Fundo da Justiça (FUNJUS) ${ }^{232}$} & $D^{233}+E^{234}$ & \multirow[t]{2}{*}{$\mathrm{X}$} \\
\hline & & & $100 \%{ }^{235}$ & \\
\hline $\begin{array}{l}\text { Rio Grande } \\
\text { do Sul (RS) }\end{array}$ & Poder Judiciário & $\begin{array}{l}\text { Fundo de } \quad \text { Reaparelhamento do } \\
\text { Poder Judiciário (FRPJ) }{ }^{236}\end{array}$ & $100 \%{ }^{237}$ & $\mathrm{X}$ \\
\hline \multirow{3}{*}{$\begin{array}{l}\text { Santa } \\
\text { Catarina (SC) }\end{array}$} & Poder Judiciário & \multirow{2}{*}{$\begin{array}{l}\text { Fundo de Reaparelhamento da } \\
\text { Justiça (FRJ) }\end{array}$} & \multirow[t]{2}{*}{$80 \%$} & \multirow[t]{2}{*}{$\mathrm{X}$} \\
\hline & Ministério Público & & & \\
\hline & & $\begin{array}{l}\text { Fundo Especial de Modernização e } \\
\text { Reaparelhamento do Ministério } \\
\text { Público }\end{array}$ & $20 \%$ & $\mathrm{X}$ \\
\hline
\end{tabular}

Fonte: Elaboração própria.

A análise dos dados coletados indica que a União e os Estados do Acre, do Amapá, de Alagoas, da Bahia, do Ceará, do Mato Grosso do Sul, do Maranhão, da Paraíba, do Rio de Janeiro, do Rio Grande do Norte, de São Paulo e do Tocantins não obedecem integralmente a regra do art. 98, § $2^{\circ}$, da CRFB, conforme as premissas apresentadas na seção 2.

${ }^{222}$ Vide Lei n. 8.876/1994/SP.

${ }^{223}$ Art. $3^{\circ}$, I, da Lei n. 8.876/1994/SP; e art. $9^{\circ}$ da Lei n. $11.608 / 2003 /$ SP.

${ }^{224}$ Art. $9^{\circ}$ da Lei n. 11.608/2003/SP.

${ }^{225}$ Vide art. $8^{\circ}$, II, 19, V, 164, XVIII, 235 e 236 da Lei Complementar n. 988/2006/SP.

${ }^{226}$ Art. 15, III, da Lei n. 4.476/1984/SP.

${ }^{227}$ Vide Lei n. 12.216/1998/PR.

${ }^{228}$ Custas dos atos do Tribunal de Justiça.

${ }^{229}$ Custas dos atos dos Juizados Especiais.

${ }^{230}$ Custas dos atos dos Secretários do Tribunal de Justiça.

${ }^{231}$ Art. $3^{\circ}$, VIII, XX e XXIV, da Lei n. 12.216/1998/PR.

${ }^{232}$ Vide Lei n. 15.942/2008/PR.

233 Taxa Judiciária.

${ }^{234}$ Custas dos atos praticados pelos serviços estatizados.

${ }^{235}$ Art. 30, I e XII, da Lei n. 15.942/2008/PR.

${ }^{236}$ Vide Lei n. 7.220/1978/RS; e art. $1^{\circ}$ da Lei n. 12.613/2006/RS.

${ }^{237}$ Art. $2^{\circ}$, $a$, da Lei n. $7.220 / 1978 / \mathrm{RS}$, combinado com art. $1^{\circ}$ da Lei n. 12.613/2006/RS.

${ }^{238}$ Vide Lei n. 8.067/1990/SC, e Lei Complementar n. 188/1999/SC.

239 Art. $3^{\text {o }}$, II a IV, da Lei n. 8.067/1990/SC, combinado com art. 2 ${ }^{\text {o }}$ § $3^{\text {o }}$, I e III, da Lei Complementar n. 188/1999/SC, com redação dada pelo art. $1^{\circ}$ da Lei Complementar n. 723/2018/SC (proposição do Poder Judiciário).

${ }^{240}$ Vide art. $6^{\circ}$ e $7^{\circ}$ da Lei Complementar n. 237/2002/SC; e art. $2^{\circ}$, $§ 3^{\circ}$, da Lei Complementar n. 188/1999/SC, com redação dada pela Lei Complementar n. 730/2018/SC.

241 Art. $2^{\circ}$, § $3^{\circ}$, I e III, da Lei Complementar n. 188/1999/SC, com redação dada pelo art. $1^{\circ}$ da Lei Complementar n. 723/2018/SC (proposição do Poder Judiciário); e art. $7^{\circ}$, II, da Lei Complementar $n$. 237/2002/SC. 
A União é incumbida de organizar e manter o Supremo Tribunal Federal, o Superior Tribunal de Justiça, a Justiça Federal, a Justiça do Trabalho, a Justiça Eleitoral, a Justiça Militar e a Justiça do Distrito Federal e dos Territórios. No entanto, a legislação federal vincula apenas as taxas cobradas pela prestação de serviços específicos e divisíveis pelos órgãos jurisdicionais da Justiça do Distrito Federal e dos Territórios. E, mesmo nesse caso, somente as Custas estão integralmente vinculadas ao Programa de Modernização e Aperfeiçoamento da Justiça do Distrito Federal e dos Territórios de Primeiro e Segundo Graus (PROJUS) (art. 83, $\S 1^{\circ}$, I, da Lei n. 11.697/2008, combinado com art. $6^{\circ}$, inciso I, alínea $a$, da Lei n. 13.500/2017). A Taxa Judiciária também é integralmente vinculada, mas apenas à Ordem dos Advogados do Brasil - Seccional do Distrito Federal (artigo $1^{\circ}$, caput, da Lei n. $6.811 / 1980)$.

O Amapá destina 8,17\% da integralidade da receita auferida a título da Taxa Judiciária e das Custas Judiciais ao Fundo Especial de Apoio e Desenvolvimento do Ministério Público do Estado do Amapá (FEMPAP) e outros 8,17\% ao Fundo Especial da Defensoria Pública (FEDP). Embora a repartição de fração dessa receita com os órgãos de execução das Funções Essenciais à Justiça seja admitida (sétima premissa), a atual redação dos dispositivos que garantem esses recursos ao Ministério Público e à Defensoria Pública do Estado (art. 11, III e IV, da Lei n. 2.386/2018/AP), foi determinada por uma lei de iniciativa do Governador do Estado (Lei n. 2.492/2020/AP), e não do Tribunal de Justiça, como exige a terceira premissa (art. 98, $\S 2^{\circ}$; e 99, caput e $\S \S 1^{\circ}$ e $2^{\circ}$, da CRFB).

Acre (5\%), Alagoas (2\%), Bahia (0,5\%), Ceará (3\%), Maranhão (3\%), Rio Grande do Norte $(2 \%)$ e Tocantins $(2 \%)$ destinam percentual das taxas cobradas pela prestação de serviços específicos e divisíveis pelos órgãos judiciários jurisdicionais que organizam e mantêm a Fundos de Segurança dos Magistrados (art. $7^{\circ}$ e $8^{\circ}$ da Resolução n. 104/2010/CNJ; e art. 19 da Resolução n. 291/2019/CNJ). Dessa forma contrariam a finalidade da regra do art. 98, $\S 2^{\circ}$, da CRFB de garantir a integralidade dessa receita tributária ao custeio dos serviços específicos da Justiça. O custeio dos serviços de segurança de Ministros, Desembargadores e Juízes até pode justificar a vinculação de parte da receita pública, desde que esta não seja oriunda da cobrança de custas e emolumentos, porque não se está diante de uma atividade típica do Poder Judiciário.

Alagoas também destina 1\% ao Fundo da Escola Superior da Magistratura do Estado de Alagoas (FUNDESMAL), contrariando a premissa do proveito direto da prestação de 
jurisdição pelo Poder Judiciário (art. 110, § 3º e 259 da Lei n. 6.564/2005/AL, e art. $5^{\circ}$, III, da Lei n. 6.687/2006/AL).

A Paraíba destina 2\% ao Fundo de Apoio ao Registro das Pessoas Naturais (FARPEN), cuja finalidade é a de compensar os registradores civis das pessoas naturais pelos atos gratuitos, na forma do artigo $8^{\circ}$, caput, da Lei n. 10.169/2000 (subitem II do item III da Tabela B da Lei n. 5.672/1992/PB, com redação dada pelo art. $4^{\circ}$ da Lei n. 8.071/2006/PB).

Já São Paulo contraria o aspecto da destinação integral das taxas cobradas pela prestação de serviços públicos específicos e divisíveis pelos órgãos judiciários jurisdicionais que organiza e mantém ao permitir que $21,67 \%$ dessa receita tributária sejam revertidos à Conta Única do Tesouro sem qualquer vinculação a ação ou programa na Lei Orçamentária Anual que atenda à finalidade do art. 98, $\S 2^{\circ}$, da CRFB (art. 15, III, da Lei n. 4.476/1984/SP; art. $3^{\circ}$, I, da Lei n. 8.876/1994/SP; e art. $9^{\circ}$ da Lei n. 11.608/2003/SP, todos interpretados a contrario sensu).

Finamente, a União (OAB-DF) e os Estados do Ceará (FRMMP/CE e FAADEP), de Mato Grosso do Sul (FUNDE-PGE e FUNADEP) e do Rio de Janeiro (FUNPERJ, FUNDPERJ e CAARJ/IAB) instituem e cobram adicionais às taxas de serviços judiciários judiciais, destinando-os às Funções Essenciais à Justiça e até a entidades privadas. Embora se enquadrem no conceito legal de tributo (art. $3^{\circ}$ do Código Tributário Nacional), na falta de autorização constitucional específica, essas exações obrigatórias contrariam o Sistema Tributário Nacional (TORRES, 2008, p. 344). Isso porque tais acréscimos não se enquadram em quaisquer das espécies tributárias admitidas (art. 145, caput; 148; 149, caput; e 149-A, caput, da CRFB). Também não configuram aumento das taxas sobre as quais incidem, porque não há acréscimo no custo do serviço que o justifique (art. 145, II, da CRFB); nem configuram novas taxas, porque o Ministério Público, a Advocacia Pública e a Ordem dos Advogados do Brasil não prestam efetiva ou potencialmente serviço público específico e divisível ao sujeito passivo da relação tributária (art. 145, II, da CRFB); e, em relação à Defensoria Pública, seus assistidos gozam de imunidade (art. 5º LXXIV, da CRFB). Não se confundem com as contribuições, porque os Estados-membros só são autorizados a instituir as previdenciárias, cobradas dos beneficiários de seus Regimes Próprios e Facultativos Complementares de Previdência Social (art. 40, $\S 14$ e 16; e 149, $\S 1^{\circ}$, da CRFB). Por fim, em relação às Caixas de Assistência dos Advogados, embora sejam órgãos da Ordem dos Advogados do Brasil (art. 45, IV, da Lei n. 8.906/1994), quando adquirem a feição de 
entidades fechadas de previdência privada ("fundos de pensão"), não podem receber aporte de recursos de quaisquer entidades públicas, salvo na qualidade de patrocinadora (art. 202, § $3^{\circ}$, da CRFB, parágrafo incluído pelo art. $1^{\circ}$ da EC n. 20/1998).

\section{CONCLUSÃO}

A conclusão é no sentido de que em 2020, que mais de quinze anos após a entrada em vigor da EC n. 45/2004, o grau de efetivação da regra do art. 98, § 2º da CRFB ainda é insatisfatório. Isso porque 13 dos 27 entes federativos incumbidos de arrecadar a receita tributária da prestação de serviços públicos específicos e divisíveis pelos órgãos jurisdicionais do Poder Judiciário descumprem a teleologia dessa vinculação constitucional (48,15\%).

Não foram recepcionados pelo art. $98, \S 2^{\circ}$, da CRFB os seguintes dispositivos: Tabela B do Anexo do Decreto-Lei 115/1967; art. $1^{\circ}$, caput, da Lei n. 6.811/1980; e art. 15, III, da Lei n. 4.476/1984/SP.

É formalmente inconstitucional, por vício de iniciativa, o art. 11, III, da Lei n. 2.386/2018/AP, com redação dada pelo art. $1^{\circ}$ da Lei n. 2.492/2020/AP.

São materialmente inconstitucionais, por incompatibilidade com a teleologia da regra do art. 98, § $2^{\circ}$, da CRFB, os seguintes dispositivos: art. 20, $\S 1^{\circ}$, da Lei n. 1.422/2001/AC, parágrafo acrescentado pelo art. $1^{\circ}$ da Lei n. 2.533/2011/AC; art. $3^{\circ}$, I, da Lei $n$. 3.586/2019/TO; art. 110, $\S 3^{\circ}$, e 259 da Lei n. 6.564/2005/AL; art. 5º, III, da Lei n. 6.687/2006/AL; art. 3ㅇ, I, da Lei n. 7.910/2017/AL; art. 4º I, da Lei n. 13.971/2018/BA; art. $4^{\mathrm{o}}$, I, da Lei n. 15.145/2012/CE e, por arrastamento, art. $3^{\mathrm{o}}$ do Provimento n. 25/2012/PRES/TJCE, com redação dada pelo art. $1^{\circ}$ do Provimento n. 12/2017/PRES/TJCE; art. $2^{\circ}$, II, $b$, da Lei n. 16.131/2016/CE; art. $3^{\circ}$ da Lei n. 12.642/1996/CE, com redação dada pelo art. $1^{\circ}$ da Lei n. 14.247/2008/CE; art. 4 , I, da Lei Complementar n. 164/2014/MA e, por arrastamento, o art. $1^{\circ}$ do Ato n. 32.015/2015/PRES/TJMA; subitem II do item III da Tabela B da Lei n. 5.672/1992/PB, com redação dada pelo art. $4^{\circ}$ da Lei n. 8.071/2006/PB; art. $4^{\circ}$, I, da Lei n. 9.920/2014/RN; art. $6^{\circ}$ da Lei n. 6.369/2012/RJ; e art. $2^{\circ}$, § $3^{\circ}$, I e III, da Lei Complementar n. 188/1999/SC, com redação dada pelo art. 1º, I, da Lei Complementar n. 723/2018/SC.

São formal e materialmente inconstitucionais, por incompatibilidade com os art. 99, caput e $\S \S 1^{\circ}$ e $2^{\circ}, 145,149$, caput, 150 , III, $b$ e $c$, e $202, \S 3^{\circ}$, da CRFB, os seguintes 
dispositivos: art. 1 ${ }^{\circ}$, I, da Lei Complementar n. 179/2013/MS; art. 31, III, da Lei Complementar n. 111/2006/RJ; e art. 4º, III, da Lei n. 4.664/2005/RJ. Ainda que esses preceitos estaduais instituidores de adicionais às taxas de serviços judiciários judiciais não representem ofensa à regra do art. $98, \S 2^{\circ}$, da $\mathrm{CRFB}$, seus vícios não permitem uma interpretação conforme à Constituição.

\section{REFERÊNCIAS}

BASSI, Camillo de Moraes. Fundos especiais e políticas públicas: uma discussão sobre a fragilização do mecanismo de financiamento. Texto para Discussão, Rio de Janeiro, n. 2.458, IPEA, mar. 2019, p. 1-60.

BRASIL. Proposta de Emenda à Constituição no 96-B, de 1992, volume II. Introduz modificações na estrutura do Poder Judiciário. Brasília, DF: Câmara dos Deputados, [1999]. Disponível em: http://imagem.camara.gov.br/Imagem/d/pdf/DCD0019991214SA2090000.PDF\#page=244. Acesso em: 2 abr. 2020.

COSTA, Leonardo da Silva Guimarães Martins da. Uma visão sistêmica dos fundos federais. Textos para Discussão, Brasília, n. 7, 2012, Tesouro Nacional. Fundos Federais - abordagem transdisciplinar diante do Projeto da Lei de Finanças Públicas. Textos para Discussão, Brasília, n. 29, 2017, Tesouro Nacional. DINAMARCO, Cândido Rangel; LOPES, Bruno Vasconcelos Carrilho. Teoria geral do novo processo civil: de acordo com a Lei 13.256, de 4.2.2016. São Paulo: Malheiros, 2016. HARADA, Kiyoshi. Direito financeiro e tributário. 26. ed. atual. ampl. São Paulo: Atlas, 2017.

HOLMES, Stephen; SUNSTEIN, Cass R. O custo dos direitos: porque a liberdade depende dos impostos. Tradução de Marcelo Brandão Cipolla. São Paulo: WMF Martins Fontes, 2019. KELSEN, Hans. Teoria pura do direito. São Paulo: WMF Martins Fontes, 2009. MENDES, Gilmar Ferreira et al. Curso de direito constitucional. 4. ed. rev. atual. São Paulo: Saraiva, 2009.

MONTESQUIEU, Barão de. Do espírito das leis. São Paulo: Martin Claret, 2015. MORAES, Alexandre de. Direito constitucional. 33. ed. rev. atual. São Paulo: Atlas, 2017. POSNER, Richard A. Economic analysis of Law. 9. ed. Chicago: Wolters Kluwer Law \& Business, 2014.

SANCHES, Osvaldo Maldonado Sanches. Fundos federais: origens, evolução e situação atual na administração federal. Revista de Informação Legislativa, Brasília, ano 39, n. 154, Senado Federal, abr./jun. 2002, p. 269-299.

TORRES, Ricardo Lobo. Tratado de direito constitucional financeiro e tributário, volume V: o orçamento na Constituição. 3. ed. rev. atual. Rio de Janeiro: Renovar, 2008. 